\title{
Mental Health Laws and Reflections on Culture: The Case of United Arab Emirates
}

\author{
Amber Haque \\ Doha Institute for Graduate Studies \\ School of Psychology and Social Work \\ Doha, Qatar
}

\begin{abstract}
This paper introduces the reader to mental health laws and concerned governmental bodies in the United Arab Emirates (UAE). The native culture and shariah laws pertinent to mental health are discussed. It is noted that the mental health sector of the country has come a long way and with new initiatives and strategies in health sector will continue to improve. Some challenges and their implications are noted with a set of recommendations.
\end{abstract}

The UAE population in 2018 was estimated to be 9.54 million, up from 2014's estimation of 9.44 million. Emirati nationals make up only ten percent of the population, and the country has the $7^{\text {th }}$ highest migration rate in the world at $12.36 \%$ (World Population Review, 2018). The population was estimated to have increased as much as $65 \%$ between 2006 and 2010, with the migration rate at $21.71 \%$ (UAE National Bureau of Statistics 2010). Established in 1971, the UAE is considered a fairly developed country given that their healthcare service infrastructure is reaching international standards. However, the national healthcare system's meeting the growing needs of the population continues to be a challenge. Experts have voiced concerns about "doing more" to address mental health issues and the stigma and negativity associated with the term mental inhibits development of effective programs in the country (Sayed, 2015; Al Darmaki \& Yaakieb, 2015; The National, Oct 2014; Al-Sayed, 2010). The stigma and the existing culture of silence results in late diagnoses of psychiatric conditions, and a belief that mental health is contagious has deterred the locals from both seeking psychiatric help and joining the field of mental health as a 
profession (Butcher, 2013; Zaman, 2011). The deficit of experts operating in the field reflects this attitude and contributed to slow development of mental health standards, quality control, and availability of professional services.

Studies show that nonscientific methods of understanding and treating mental health problems -- such as the power of the evil eye and the belief that mental health problems indicate a weakness in an individual's religious faith -- are still strong (Al-Darmaki \& Sayeed, 2015; Chowdhury, 2011; Gerstein et al., 2009). Additionally, traditional approaches of understanding and treating mental health are popular (Haque \& Al Kindi, 2015). Mental illnesses in UAE are also increasing, yet 55\% of mental health patients deny they are ill, mainly because of the stigma attached to the condition (Gulf News, 2011). Mental health is now identified among the top five serious health concerns along with obesity, cardiovascular diseases, diabetes, and cancer (Al Karam \& Haque, 2015; The National, 2014). The extreme shortage of mental health projects and concerns for long waiting lists in public hospitals is voiced in local media (Abed, 2014).

There are minimal statistics on the prevalence of psychological disorders in the country, but estimates show that approximately $75 \%$ of psychological conditions are related to anxiety and depression (Mesbah, 2009), up to $4 \%$ of the population could be clinically depressed, and mild depression may be affecting up to $15 \%$ of the residents (Gulf Business, 2016).

According to the World Health Organization (2006), the UAE, Kuwait, and Qatar have much lower numbers of mental health professionals per 100,000 people in relation to the global average (Chowdhury, 2011). For example, there are 0.3 psychiatrists in UAE compared to 7.79 in the United States, 0.51 psychologists compared to 29.03 and 0.25 social workers compared to 17.93 mental health professionals per 100,000, with 25 beds reserved for psychiatric patients in the general hospitals, and 80 beds available in the specialized mental hospital. This pales in comparison to neighboring Saudi Arabia whose total number of mental health workers is 22 per 100,000. By profession, this breaks down to 3 psychiatrists, 13 nurses, two psychologists, three social workers, and one other mental health worker. In terms of support for child and adolescent mental health, $15 \%$ of primary and secondary schools have either part-time or full-time school counselors.

Of equal concern is the apparent lack of integration of service sectors in different parts of the country charged with managing the mental health needs of the population. Until a few years ago, there were over 300 healthcare personnel in the mental health system working without a license (Nereim, 2012). These concerns led the author to explore developments in the mental health system in UAE including the laws and cultural issues. 


\section{Development of Mental Health Laws and Governing Bodies}

The Department of Health and Medical Services in the UAE was instituted in Dubai in the 1970s and specialized psychological services were initiated for patients in 1975 (Jabbour \& Yamout, 2012). Individuals suffering from mental conditions such as agitation or aggressive behaviors received medical attention in facilities guarded by the Dubai Police and security officers, and when violent tendencies were exhibited, the nurses chained the patients (Jabbour \& Yamout, 2012).

The United Law No. 28 issued in 1972 was the first document that referred to mental patients and it was the first time the term "psychosis" was defined locally in accordance with modern medical terminology (Haque \& Al Kindi, 2015). In 1983, Al Amal Hospital was opened in Dubai (Gulf News, 2011). In Abu Dhabi, psychiatric patients were initially admitted in Central Hospital that was named Shaikh Khalifa Medical City in 2005, which took 41,000 patients in 2016 alone between age groups 2 to 100-years-old (The National, 2017).

\section{Federal Laws Associated with Mental Health}

Several federal laws and decrees from the government started to shape the development of mental health. Federal Law 28 (1981) addressing detention of psychotic patients, Federal Law 43 (1993) addressing correctional institutions, and Federal Law 14 (1995) addressing drugs and mind influencing substances were issued. These laws were followed by periodic Ministerial Decrees: Decree 1350 (1994) regarding the assessment of inmates with psychotic disorders and other disorders threatening their lives and those of others, Decree 444 (1997) regarding the formation of a Central Committee for Mental Health, Decree 1090 (1998) regarding the internal organization of addiction treatment facilities in the UAE, Decree 1826 (1998) regarding the formation of the computerization of medical records, and Decree 274 (1998) regarding the formation of the Appealed Mental Health Board.

The UAE was one of the first countries in the region to develop a Mental Health Act through its Decree 28 (1981) and updates were made periodically until 2009, when a group of psychiatrists proposed a set of regulations to further improve the system. The final version was submitted to the National Council in 2011 and is pending review and approval.

In 1981, the President signed one federal law relating to mental illness (Federal Law 28) and another relating to mental disability (Federal Law 29). These laws together with the professional codes of conduct remain the principal legislation specific to mental health (Alhassani \& Osman, 2015). Federal law 28 has 12 articles dealing primarily with definitions of key terms such as 
voluntary and involuntary admissions and the roles of individuals such as relatives, police, the courts, and the medical board. It clarifies the types, conditions, and procedures for patient admission in mental health facilities. The first part defines the mental health facility and the patient and includes all spectrums of mental health issues. It distinguishes between assessment and treatment that may be offered by licensed professionals from disciplines including psychiatry, clinical psychology, social work, nursing, counseling, and occupational therapy. Subspecialties such as forensic and community services are also defined. The second part of the law addresses goals and objectives, as well as guidelines and standards that would govern the relationship between mentally ill patients and others. The law incorporates representation of the General Counsel of Mental Health in addition to the legal and administrative members, psychiatrists, clinical psychologists, psychiatric social workers, and psychiatric nurses. This inclusion signifies the increasing attention to other practicing professions and the move towards a biopsychosocial model that adopts a more holistic approach to treating patients. The proposed law also mandates a Standards Review Board charged with monitoring and reviewing monthly reports from mental health facilities regarding admissions against will and appeals made by patients or their relatives. The General Counsel of Mental Health is sanctioned as the licensing board of UAE, inspecting and evaluating various facilities for adherence to law and expected standards. A section of the proposed law discusses the rights of mentally ill patients on issues of confidentiality, respect, humane treatment and management, protection against harm as well as the freedom to practice religious acts. Patients' rights to optimum care in the closest to residence facility, prescription of medication, patients' rights to be informed about all health care professionals managing their case as well as of important decisions that need to be made are also documented. The law specifies that the patients should be made aware of treatment options and sources of the financial coverage and obligations and stipulates that a copy of the patient's rights should be kept in their files. The proposed law also incorporates guidelines on performing neurosurgery, hormonal treatments for gender identity cases, treating and managing minors, and malpractice in mental health services.

Federal law 29 has nine articles that define disability and outline the rights of persons with mental disabilities. It includes definitions of persons with reduced mental abilities and guarantees rights for services. This law also ensures the right to freedom of speech and communication, protection of medical records and personal affairs, and access to educational and training centers in preparation for integration into the society (Alhassani \& Osman, 2015). Three more laws are currently under development. The first covers definitions of mental illness, objectives, patient rights, types of admission, patient management, etc. and recommendations from the World Health Organization's Eastern Mediterranean Region (Abou-Saleh, 2012). The second law is about the 
rights of elderly and covers issues of abuse, neglect and medical insurance and the third law (known also as the Wadima Law named after an 8-year old Emirati girl who had died from abuse by her father), is made to ensure legal rights of minors.

\section{Governmental Regulatory Bodies and Associations}

The Ministry of Health (MOH) officially manages health care legislation in the country (Al-Darmaki \& Yaaqeib, 2015). With an increase in the number of health care institutions, two semi-governmental bodies were established to regulate their respective Emirates. The Health Authority of Abu Dhabi (HAAD) established in 2001, is the regulatory body of Abu Dhabi, and oversees all government-sponsored hospitals and monitors private health care providers in Abu Dhabi. HAAD requires psychologists who practice in Abu Dhabi to hold a doctoral or master's degree, submit attested documents confirming experience and competence and pass licensing exams. The National Rehabilitation Center (NRC) established in Abu Dhabi in 2002 also provides treatment, rehabilitation, research, prevention, human capacity building, policy and legislative development, and advocacy for clients needing services for substance addiction (Wanigaratne, 2012).

In 2007, the MOH established the Dubai Health Authority (DHA) to independently regulate the health care system in Dubai including mental health services. Healthcare facilities in Dubai are licensed and inspected by the Health Regulation Department (HRD), a wing of the DHA responsible for licensing healthcare professionals to practice in Dubai. The Dubai Strategy 2015 lays a strong foundation for effective healthcare regulation, raising standards in par with international levels. With regards to psychology, the DHA requires that practitioners hold a doctoral degree in psychology from an accredited institution of higher learning. Considerations are made for master's degree holders who graduate from psychology-focused programs (minimum two years), successfully complete an internship, and acquire two years of experience in their designated field. To accommodate expatriates who graduate from the UAE University, trainee regulations have been developed by HAAD and in process at DHA. The DHA has also laid out a strategic plan for mental health initiatives during 2016-2021, available at the following website: https://www.dha.gov.ae/ Documents/Dubai_Health_Strategy_2016-2021_En.pdf.

The Community Development Authority (CDA) was established in 2013 to develop a framework for social development and social services in Dubai and delivers plans necessary for their functioning, setting up policies and procedures and standards for social service providers. The $\mathrm{MOH}$ regulates the healthcare system in all the other Emirates. The Emirates Psychological Asso- 
ciation (EPA) established in 2003 in Dubai by the Ministry of Social Affairs is the only officially recognized professional association for psychologists in the UAE and aims to raise awareness of mental health issues in the country (Kruse, 2011). It serves also as a liaison between government departments and private sector to better serve the community (Al-Darmaki \& Yaaqeib, 2015).

It should be noted that the various government bodies including the Ministry of Health, have made great strides over the years and are constantly trying to improve the quality of mental health services at all levels. However, a lack of coordination among them and abrupt change of policies within each agency has been challenging for mental health professionals. Additionally, the lack of efforts by EPA in streamlining psychological services is discouraging.

\section{Reflections on Cultural Practices}

For professionals not familiar with the culture of UAE, it is important to know that the basic values and traditions of an Arabic and Muslim society are inherently different compared to the western paradigm and the significance of cultural variables in assessment and treatment cannot be understated (Thomas, 2015). There are at least two issues in relation to culture that are worthy of consideration. First, culture plays a role in the way symptoms are expressed based on the belief and value system that operates within that culture. Significant differences exist between the symptoms presented by non-Western clients who belong to more conservative cultures as opposed to most Western clients. Secondly, differences in culture also influence perception of disorders with regards to causes and treatment (Haque, 2014; Al-Darmaki, 2011; Haque, 2010; 2008). Researchers have documented trends among Arabs and some other nonWestern cultures that their psychological distress is expressed in somatic ways and it is presumed that cultural stigma toward mental health can be mitigated by shifting the focus on physical symptoms. In one interesting research, investigators found out that somatization is not due to stigma of mental health but lack of formal education (Gureje, Simon, Ustun, \& Goldberg, 1997). It is also common knowledge about local culture that it does not encourage its people, especially men, to express emotions or center on oneself, hence people avoid bringing up conversations on psychological ailments.

Since the population of the UAE is predominantly Muslim, features common to majority Muslim cultures should be recognized. These include the following: a) collectivism, where family interdependence and loyalty are strongly emphasized, b) patriarchal and hierarchical nature of societies where decision making is delegated to the authorities, c) behaviors are determined more by norms and group goals than personal rights and choices, and d) traditional values carry more weight than westernized or progressive ideas which are in 
fact, perceived as a threat to the social identity (Pridmore \& Pasha, 2004). The UAE National Charter 2021 aims to further emphasize family relationships, communication between family generations, and preservation of traditional principles of marriage (UAE National Charter, 2010).

Dwairy (2007) raises an interesting point that the Arab and Muslim individual may not develop an independent ego identity because he/she is always a part of the larger family and the main conflict for these groups is in intrafamilial domain rather than intrapsychic one and therefore, there is a need to understand the social mechanisms more than the defense mechanisms often explored by psychotherapists. In traditional Arab culture, intelligence refers to morals and values rather than logic and reasoning and wisdom learned from the elders is more important than worldly knowledge. Interpersonal skills and respect for others, especially the elders, have high value in Emirati culture so coaching a local to be assertive with parents or family will be contradictory with cultural norms. Also, in cultures of dominant family influence, there are different perceptions between the client and family members as to what is causing the problem. Unlike Western cultures, an Arab client's entire family may come for consultations with the therapist and therapist's encouragement for the client to make their own decisions may irritate the family. It is helpful if the therapist, client, and the client's family agree on perceived causes, descriptions, and treatment of presenting problems.

An interesting point was raised by Katsavdakis and colleagues (2001), that persons raised in Arab traditions tend to use language to hide pathological conditions when asked to communicate in an acquired language as opposed to their native language. Similarly, Mahmood and Ahmed (2016), emphasize the use of etic tests for assessing Arabs because such measurements are based on large standardized samples. They lament about the use of translated versions of MMPI and other popular psychological tests in the Arab world and caution that the results may be cross-culturally meaningless. Many issues related to mental health and culture in UAE are presented in a seminal book edited by $\mathrm{Al}$ Karam and Haque (2015).

\section{Mental health and Shariah}

It is necessary also to be aware of religious laws related to mental health as religious law of Islam is embedded in the laws of most Muslim countries. Chaleby (2001) writes that most Muslim countries apply sharia as a guiding principle of their professions, including mental health. The implications of sharia on mental health is broad, but a few issues that stand out in contrast with the secular law are discussed below.

The legal system in most Islamic countries is derived from British or other 
European legal traditions as a result of colonialism, except in matters of personal status, family relationship, and inheritance laws. While secular law emphasizes a health professional's legal rather than moral obligations, Islam makes no formal distinction between legal and moral duties. A doctor for instance, is obliged to provide free medical care if the patient cannot afford to pay and is under ethical and legal obligation to provide continuous care for a patient until the services are appropriately terminated.

In areas of insanity defense and criminal responsibility, Islamic law states that a crime is not a crime absent of intent. Thus, an insane person is considered to lack intent because of a disturbed thought process and is not liable for the crime committed.

With regards to patient confidentiality in sharia, a clinician may not be required to testify against the patient and a doctor forced by law to disclose confidential matters. Sharia also divides mental competence into two: the competence of entitlement and the competence of performance. The age of mental competence, entering a contract, committing oneself to a mental hospital, and making a will are generally different from secular law. The issue of interdiction upon a person and guardianship rules for the mentally ill vary based on the views of different sharia schools.

For child custody, secular law includes legal guardianship, whereas in shariah, there is a difference between custody (caring/residential responsibility) and legal guardianship (full responsibility for child's welfare, including decisions for money, contracts, and career). Legal guardianship always belongs to the father. The custody of a male child is the right of the mother until the child can take care of his/her own self, which has been approximated at seven years of age. In the case of a female child, the mother's rights of custody extend until the child reaches puberty, with rights being subject to conditions such as remaining faithful and being attentive to her children. Most Islamic jurists consider the "best interest of the child" as the main objective in granting child custody. The right to life is inherent in the tenets of Islam and life cannot be taken without justification. Suicide including euthanasia is a major sin and is unlawful in sharia. One must remember that sharia contributes to UAE laws but is not the only source. If there are specific provisions for a certain issue, the courts will follow that provision, but in the absence of such a provision, sharia laws may prevail.

\section{Implications and Recommendations}

While the overall progress in healthcare sector of UAE is undeniably impressive, the local culture and traditions have significant impact on the development of a progressive mental health system at par with international standards. 
The government has followed up on the WHO's suggestions of providing services that are easily accessible to more people and conducting public education through mental health awareness campaigns (World Health Report 2011). However, the proposed Mental Health Law has yet to see the light of the day and it is hoped that the various government bodies will work in tandem with the MOH to form a unified national policy and procedures on mental health. What ensued in the last seven years to the proposed law is not clear, as no information could be obtained about it. Despite such shortcomings in the public sector, the private sector has advanced rapidly to fill the gap in mental health services. Dozens of private psychiatric clinics have opened in the last decade and are taking care of mental health needs of citizens and residents who could have waited longer for services at public hospitals. The private clinics and centers also meet the needs of those who consider private clinics of higher quality, can afford to pay more and see a professional on demand. However, a lack of clear directives, slow process of issuing licenses, and overall bureaucracy in the government sector discourages qualified candidates from joining the workforce. A dearth of academic and training programs is yet another reason for relatively slow growth of mental health development in the country and lack of awareness of scientific basis for mental illnesses and stigma is hampering growth of related disciplines. With newer strategies and priorities, it is hoped that the scenario will change in coming years. A society ingrained in tradition and culture of its own has made tremendous progress and more positive change is on the horizon. It is essential for practitioners to be aware of cultural nuances to protect both the image of profession and rights of clients. The government may consider cultural competency requirements for mental health practitioners and provide ongoing cultural competency education.

\section{Acknowledgements}

I am indebted to Badriya Al Kindi from Abu Dhabi Psychiatric Hospital for providing me with English translation of mental health laws and obtaining relevant information from hospital administration and other relevant authorities. My students Vanessa Baba Dadzie and Raabia Haque also assisted in the write up of this article. The lack of citations and other deficiencies in this paper are my own.

\section{References}

Abed. A. (2014). 33 thousand mental patients suffering from shortage of psychotherapists. In Al-Darmaki and Yaaqeib, S.I. (2015), Psychology and mental health services in the UAE. Psychology International. American Psychological Association. 
Abou-Saleh, M.T. (2012). The World Federation for Mental Health: building its constituency in the East Mediterranean Region for improving care and the lives of the mentally ill and their families. Arab Journal of Psychiatry, 23, 178-184.

Al-Darmaki, F., \& Yaaqeib S.I. (2015). Psychology and mental health services in the United Arab Emirates. Psychology International Newsletter, 26(2). Retrieved from http://www.apa.org/international/pi/2015/06/index.aspx

Alhassani, G. \& Osman, O.Y. (2015). Mental health law profile of United Arab Emirates. BJPsych International, 12(3), 71-72. https://doi.org/10.1192/S2056474000000489

Al-Karam, C. Y., \& Haque, A. (2015). Mental Health and Psychological Practice in UAE. Palgrave Macmillan. https://doi.org/10.1057/9781137558237

Al-Sayed, T. (2010). The UAE suffers from extreme deficiency in mental health facilities. Elaf. Retrieved from https://elaph.com/Web/news/2010/12/619159.html

Butcher, E. (2013). Country Focus: Mental health care in the UAE. Cyber Therapy and Rehabilitation. Retrieved from http://www.cybertherapyrehabilitaiton.com/pastissues/issue-\%203-2011/country-focus-mental-health-care-in-the-uae/

Chaleby, K. (2001). Forensic psychiatry in Islamic Jurisprudence. The International Institute ofIslamic Thought, London: UK.

Chowdhury, F. (2011). Beliefs hinder treatment of mental illness in UAE. Retrieved from http://www.khaleegtimes.com/DisplayArticle08.asp?xfile=data/theuae/2011/October/theuae_October219.xml\&section=theuae

Dwairy. M. (2007). Counseling and Psychotherapy with Arabs and Muslims: A Culturally Sensitive Approach. Teachers College Press.

Gerstein, L.H., Heppner, P.P., Aegisdottir, S. Alvin Leung, S.M., \& Norsworthy, K.L. (2009). International Handbook of Cross-Cultural Counseling: Cultural Assumptions and Practices. CA: Sage Publications, Inc.

Gulf Business (2016). Why UAE companies must address mental health issues. Retrieved from http://gulfbusiness.com/why-uae-companies-must\%20addressmental-health-issues/

Gulf News (2011). Inside a mental hospital. UAE Health. Retrieved from https://gulfnews.com/uae/health/inside-a\%20mental-hospital-1.792150

Gureje, O., Simon, G.E., Ustun, T.B., and Goldberg, D. (1997). Somatization in cross cultural perspective: A World Health Organization Study in primary care. American Journal of Psychiatry, 154(7), 989-95. https://doi.org/10.1176/ajp.154.7.989

Haque, A. \& Al Kindi, B.A. (2015). Mental health System Development in the UAE. In Mental Health and Psychological Practice in the United Arab Emirates, pp. 23-24. Palgrave Macmillan, New York. https://doi.org/10.1057/9781137558237_3

Haque, A. \& Keshavarzi, H. (2014). Integrating indigenous healing methods in therapy: Muslim beliefs and practices. International Journal of Culture and Mental Health, 7(3), 297-314. https://doi.org/10.1080/17542863.2013.794249

Haque, A. (2010). Mental health concepts in Southeast Asia: Diagnostic considerations and treatment implications. Psychology, Health and Medicine, (15)2, 127-134. https://doi.org/10.1080/13548501003615266

Haque, A. (2008). Culture bound syndromes and healing practices in Malaysia. Journal of Mental Health, Religion, and Culture. 11:7, 685-696. https://doi. org/10.1080/13674670801958867

Health Authority of Abu Dhabi (2014). Retrieved from http://www.haad.ae/haad/tab$\mathrm{id} / 58 / \mathrm{ctl} /$ Details/Mid/417/ItemID/463/Default.aspx

Dubai Health Authority. (2014). Healthcare Professionals Qualification Requirements. Retrieved from https://www.dha.gov.ae/Documents/HRD/Healthcare\%20Professionals\%20Qualification\%20Requirements\%20(PQR)\%202014-1.pdf 
Jabbour, S. and Yamout, R. (2012). Public health in the Arab world. Cambridge: Cambridge University Press.

Katsavdakis, K., Sayed, M., Bram, A., \& Brand-Barlett, A. (2001). How was this story told in the mother tongue?: An integrative perspective. Bulletin of the Menninger Clinic, 65(2), 246-265. https://doi.org/10.1521/bumc.65.2.246.19403

Kruse, M. (2011). Emirates psychological association: A brief introduction. The UAE Psychologist, Vol. 1(2), 6.

Mesbah, R. (2009). 75\% of mental illness cases in UAE are linked to anxiety and depression. Retrieved from http://www.ameinfo.com/201585.html

Nereim, V. (2012), October 14). Hundreds of Dubai care professionals working without license. The National. Retrieved from http://www.thenational.ae/news/uae-news/ hundreds-of-Dubai-care-professionals-working-without-license

Pridmore, S. and Pasha, M.I (2004). Psychiatry and Islam. Australasian Psychiatry, 12(4), 380-385. https://doi.org/10.1080/j.1440-1665.2004.02131.x

Sayed, M.A. (2015). Mental Health Services in the United Arab Emirates: Challenges and Opportunities. International Journal so Emergency Mental Health and Human Resilience, 17, 3, 661-665. https://doi.org/10.4172/1522-4821.1000263

The UAE Psychologist Newsletter (2012). DHA Psychology SME Panel: 2008 and Today. Retrieved from https://www.academia.edu/1509152/The_UAE_Psychologist_Newsletter_May_2012

The National (2017). Retrieved November 22 from https://www.thenational.ae/uae/ health/psychiatric-services-in-the-uae-on-the-brink-doctors-say\%20as-they-demand-more-investment-1.6834

The National (2014). Retrieved November 22 from https://www.thenational.ae/uae/ health/mental-health-needs-resources- 1.327286

UAE National Charter 2021. Retrieved November 22, 2018. http://dubai.ae/en/Lists/ FAQ\%20\%20List/DispForm.aspx?ID=51

Thomas, J. (2015). Psychological Wellbeing in the Gulf Countries: The New Arabia Felix. Palgrave Macmillan.

Wagaratne, S. (2012). The UAE Psychologist Newsletter, 1(2), 14-15. Retrieved from https://www.academia.edu/1509152/The_UAE_Psychologist_Newsletter_ May_2012

World Health Organization. (2011). Mental health atlas. Department of Mental Health and Substance Abuse, World Health Organization. United Arab Emirates. Retrieved from http://www.who.int/mental_health/evidence/atlas/profiles/are_mh_ profile.pdf

World Health Organization. (2006). Mental health in the Eastern Mediterranean Region; Reaching the unreached. Cairo: WHO Regional Publications.

Zaman, S. (2011). Psychiatric disorders: Thousands waiting for help in Abu Dhabi. Retrieved from https://gulfnews.com/uae/health/psychiatric-disorders-thousandswaiting-for-help-in-abu-dhabi-1.951344 
